December - 2016

\title{
Coordinated Implicitly? An Empirical Study on the Role of Social Media in Collaborative Learning
}

\author{
Xi Zhang ${ }^{\text {1* }}$, Hui Chen², Patricia Ordóñez de Pablos ${ }^{3}$, Miltiadis D. Lytras ${ }^{4}$, and Yongqiang Sun* \\ 1,2Tianjin University, China, ${ }^{3}$ University of Oviedo, Spain, ${ }^{4}$ The American College of Greece, Greece, 5 Wuhan University, \\ China \\ *Corresponding author: Xi Zhang, jackyzhang@tju.edu.cn; Yongqiang Sun, sunyq@whu.edu.cn
}

\begin{abstract}
As social media is widely adopted in collaborative learning, which places teams in a virtual environment, it is critical for teams to identify and leverage the knowledge of their members. Yet little is known about how social media influences teams to coordinate their knowledge and collaborate effectively. In this research, we explore the roles of two kinds of social media activity - information processing and social connection in teamwork - by applying communication and transactive memory systems (TMSs) as the mechanisms of explicit and implicit coordination respectively. We test this model using partial least squares (PLS) method by treating team as the unit of analysis. Drawing on the data from a study that involves 40 teams of graduate students performing a complex research report over eight weeks, we find that both TMSs and communication can significantly improve teamwork outcomes, and communication can help teams to better coordinate implicitly. With regard to social media activities, the results reveal that both information processing and social connection can enhance the level of TMSs; however, only social connection is positively related to communication. Unfortunately, information processing cannot significantly strengthen communication quality. The possible reasons are discussed and some theoretical and practical implications are also put forward.
\end{abstract}

Keywords: social media, implicit coordination, transactive memory systems, communication, teamwork outcomes

\section{Introduction}

Contemporary education theory suggests that learning, whether formal or informal, occurs most effectively when learners are actively coproducing content, socially involved in the process, or seeking information to solve problems (Dabbagh \& Kitsantas, 2012). In order to motivate students to discover 
and create new knowledge, collaborative learning is adopted in higher education classes for students to work together on a common complex and authentic task without direct intervention by teachers (Cooley, Burns, \& Cumming, 2015). Meanwhile, as social media is easily accessible to people, learning in the context of social media (e.g., Wechat, Facebook) is ubiquitous in college experience (Chen \& Bryer, 2012; McLoughlin \& Lee, 2010). Students learn from connecting to others' knowledge through various kinds of social media, rather than just from the contents defined by instructors in classroom. Therefore, the traditional classroom-based model of higher education has been significantly enriched by this new technology to become more open and collaborative-dynamic (Casey \& Evans, 2011). In addition, social media use facilitates students' collaborative activities and connections with peers across time and space, thus, making the learning process free and distributed, however, it also makes a team more distant and "virtual," and this poses a particular challenge for knowledge coordination.

Successful collaborative learning usually requires intensive knowledge, which is inherently rooted in individual members' experience and expertise, to be integrated in problem solving, leadership, writing and presentation, and so on (Prichard, Stratford, \& Bizo, 2006). Therefore, coordination is inevitable in this process to rationally use each team member's abilities to achieve task attainment and fulfill team member's personal learning goals at the same time. Recent studies on social media in learning reveal that it offers an advantage in improving students' collaborative learning abilities as well as enhancing learning performance in open and distributed learning (Al-Rahmi \& Othman, 2013; Wheeler, Yeomans, \&Wheeler, 2008). However, how social media facilitates this distributed collaborative learning process is still vague. Specifically, little is yet known about:

1) How does social media affect knowledge coordination?

2) What is the impact of different coordination mechanisms on teamwork outcomes in this context of social media supported collaborative learning?

To address these questions, we adopt the framework of team explicit and implicit coordination from the research of Espinosa, Lerch, and Kraut (2004), and draw on the notion of communication and transactive memory systems (TMSs) as the mechanisms of explicit and implicit coordination respectively, to investigate how use of different social media activities influences teamwork performance. The rest of this paper is organized as follows. We begin by reviewing prior literatures on social media, teamwork outcomes, and team coordination, followed by the development of our research model and hypotheses. We then describe the methodology and key results. Finally, we conclude our paper with theoretical and practical implications as well as limitations.

\section{Literature Review}

\section{Social Media Use in Collaborative Learning}

Social media is defined as "a group of Internet-based applications that build on the ideological and 
technological foundations of Web 2.0, and that allow the creation and exchange of user-generated content" (Kaplan \& Haenlein, 2010, p. 61). Prior studies suggest that users' most common incentives for employing social media are information, entertainment, and social aspects (Shao, 2009; Stafford, Stafford, \& Schkade, 2004); based on these incentives, researchers divided social media activities into three categories, namely, social connection, information processing, and entertainment (Heinonen, 2011). Considering that students mainly adopt social media for plans, question discussions, and other task-oriented interactions as well as for better understanding their team members, building ties, and other relationship-oriented activities in this distributed collaborative learning. Thus, we divide social media activities into information processing and social connection in this research.

Much of the existing literature examines the potential effect of social media on pedagogical benefits and knowledge management in open and distributed learning (Al-Rahmi, Othman, \& Yusuf, 2015; Mbati, 2013; Leonardi, 2014). For example, studies found that social media, such as online blogs, have the potential to improve constructivist and observational learning (Mbati, 2013). Al-Rahmi et al. (2015) claimed that social media use can enhance students' academic performance through facilitating collaborative learning. Moreover, the literature suggests that social media can provide users with four affordances, which are visibility, editability, persistence, and association (Treem \& Leonardi, 2012). It is believed that some organizational processes (e.g., knowledge management) can be well explained by these four affordances of social media. Furthermore, Leonardi (2014) proposed a theory of communication visibility, which can be made possible by social media, and which then leads to students' accurate meta-knowledge of "who knows what" and "who knows whom" (Leonardi, 2015).

\section{Teamwork Quality and Collaborative Learning Outcomes}

In the context of open and distributed learning, the success of collaborative learning not only depends on the extent to which the task is completed, but also on the extent to which team members' motivation and ability to engage in future teamwork is increased. Many prior studies have acknowledged the conceptualization of teamwork performance as a multi-variable construct (Van den Bossche, Gijselaers, Segers, \& Kirschner, 2006), and many scholars differentiated it between task-related performance and person-related performance (Hoegl \& Gemuenden, 2001). For example, Al-Rahmi et al. (2015) measured the outcome of collaborative learning in higher education from performance and satisfaction of learners. This distinction is also adopted in this research: we measure teamwork outcomes from two aspects - task performance and personal success (Hoegl \& Gemuenden, 2001).

Generally, the success of teamwork in collaborative learning is decided by how well team members collaborate and the quality of interactions in team, namely, teamwork quality (Hoegl \& Gemuenden, 2001). Among the six facets of teamwork quality (coordination, communication, balance of members' contributions, mutual support, effort, and cohesion), coordination is regarded as the essential component for successful collaborative learning in an open and distributed learning environment (Dehler, Bodemer, Buder, \& Hesse, 2011; Lin, Szu, \& Lai, 2016), and it is hard to achieve because of possible causes like social loafing and sucker effect (Kwon, Hong, \& Laffey, 2013). In addition, it is also the perspective that widely adopted by many scholars to investigate the relationship between team 
behaviors and collaborative learning performance (Kwon et al., 2013). Considering that teamwork in collaborative learning is a knowledge-intensive process, heterogeneous knowledge as well as skills are needed to complete those interdependent tasks; thus, coordination activities are dominant and inevitable in the teamwork process. As a result, we mainly focus on coordination rather than all six aspects of teamwork quality in this research.

\section{Explicit Coordination and Implicit Coordination in Collaborative Learning}

Studies on online collaborative learning indicated that it is hard to achieve effective collaborative learning solely by gathering students together. Coordination is usually defined as "the process of managing dependencies between activities" (Malone \& Crowston, 1994, p. 87). According to the visibility of coordination activities, Rico, Sánchez-Manzanares, Gil, and Gibison (2008) divided coordination into explicit coordination and implicit coordination. Explicit coordination refers to team members' intentional use of explicit manners, such as communication, to seek information, define tasks and responsibilities, and articulate plans and deadlines to accomplish the shared goals (Espinosa et al., 2004; Malone \& Crowston, 1994). In contrast, implicit coordination focuses on teams' capability to act in concert by predicting the requirements of team members, and accordingly adjust behavior without excessive communication (Espinosa et al., 2004; Rico et al., 2008). Therefore, the two basic dimensions of implicit coordination are anticipation and dynamic adjustment (Rico et al., 2008).

It is obvious that the focus on explicit coordination is prevalent in previous research on collaborative learning (Ravenscroft, 2011), which proves its undoubted importance. However, some studies acknowledge that "good coordination is nearly invisible" (Malone \& Crowston, 1994, p. 90) and give more concerns to implicit coordination in open and distributed learning, for example, drawing on the notion of implicit coordination. Researches reveal that group awareness can improve learning participation and interaction in computer supported collaborative learning (Dehler et al., 2011; Lin et al., 2016). But this does not mean that these two coordination mechanisms are opposite (Kotlarsky, Van Fenema, \& Willcocks, 2008; Rico et al., 2008). Instead, prior research suggests that "good coordination is a subtle mixture of explicit and implicit coordination" (Godart et al., 2001, p. 138), so these two kinds of coordination process can exist at the same time, and well-developed explicit coordination can leverage the development of implicit coordination (Kanawattanachai \& Yoo, 2007).

Prior research about the explicit coordination mechanism suggests that team members coordinate explicitly by using task organization mechanisms or by communicating (Faraj \& Sproull, 2000; Malone \& Crowston, 1994). However, task organization mechanisms such as planning and scheduling are less effective when the task has no or few routines because dependencies can no longer be managed in a programmed way (Espinosa et al., 2004). Therefore, in our research about collaborative learning, we focus on communication as the main explicit coordination mechanism, and it is also the dominant manner adopted by students.

Previous research about the implicit coordination mechanism suggests the importance of team members "being on the same page" (Fisher, Bell, Dierdorff, \& Belohlav, 2012; Kotlarsky, van den Hooff, 
\& Houtman, 2013), namely, that students hold a similar cognitive structure. One of the most often adopted team cognitions is transactive memory systems (TMSs), which refers to a specialized division of team members in encoding, storage, and retrieval of knowledge from different domains and team members know the locations of knowledge (Wegner, 1987). Compared to some other team cognitions (e.g., team mental modes) that overemphasize the overlapping perspective of contents conceptualized by team members, TMSs also puts emphasis on the complementary perspective (Mohammed \& Dumville, 2001). That is, TMS involves a cooperative division of members specialize in learning, remembering and sharing different knowledge (DeChurch \& Mesmer-Magnus, 2010; Ren \& Argote, 2011), and studies have revealed that TMSs can improve team performance even in distributed and virtual environment (Griffith \& Neale, 2001; Kanawattanachai \& Yoo, 2007). Given that collaborative learning is a process full of creativity, which requires heterogeneous knowledge, only common understanding about teamwork is not enough. Therefore, we think TMSs is more appropriate to be treated as an implicit coordination mechanism in our study.

Then, taken together, we propose that the two kinds of coordination as teamwork quality through which social media use in collaborative learning have an effect on teamwork outcomes. That is, the two common usages of social media activities can influence the development of communication and TMSs, and, further, influence the outcomes of both task performance and personal success. Figure 1 depicts our research model.

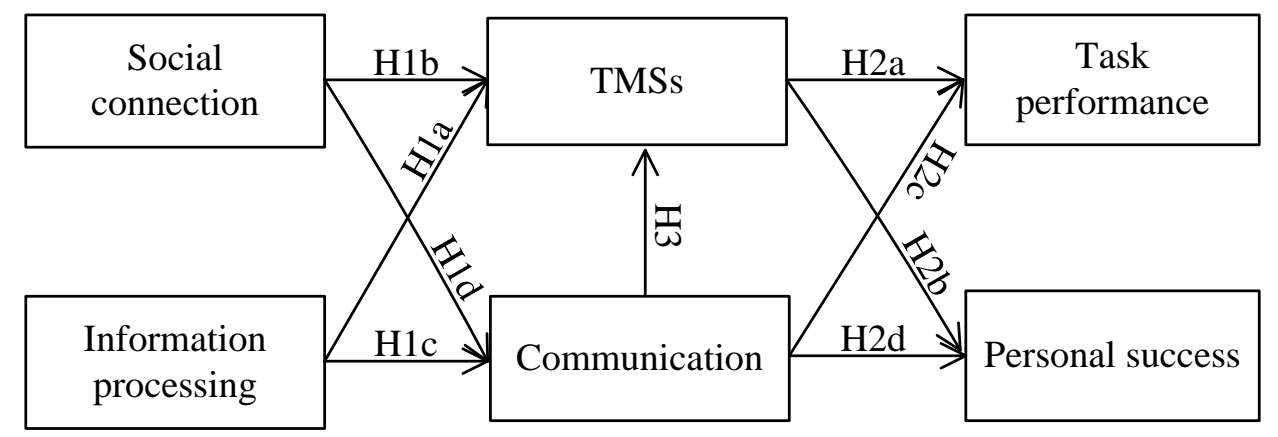

Figure 1. Research model and hypotheses.

\section{Theoretical Development}

\section{The Impact of Social Media Use on TMSs and Communication}

According to the theory of communication visibility proposed by Leonardi (2014), social media provides a forum that can facilitate public interaction among team members in open and distributed learning setting (DiMicco et al., 2008) and makes the information processing visible to other students not involved in the communication (Kietzmann, Hermkens, McCarthy, \& Silvestre, 2011; Leonardi \& Treem, 2012). Therefore, students can learn vicariously from communication occurring amongst 
their team members (Leonardi, 2015), and then identify the location of knowledge and skills they need to carry out the task. Consequently, this enhances the development of TMSs. Besides, social media provides personal profiles that are visible to others, enabling students to know "who knows what" (Leonardi, 2014) and identify those who share the same specialty in their team and then, by establishing a social connection with these people, improve the level of familiarity among team members. This leads to the formation of beliefs about members' ability and reliability to carry out the task (Gibbons, 2004). As a result, social connection activities can contribute to the formation of TMSs. Therefore, we hypothesize that:

Hypothesis 1a: Information processing is positively related to the level of TMSs in collaborative learning.

Hypothesis 1b: Social connection is positively related to the level of TMSs in collaborative learning.

The quality of team communication is often measured by frequency, formalization, structure, and openness of the information exchange (Hoegl \& Gemuenden, 2001). Good team communication should be moderately extensive, spontaneous, informal, and open. As social media makes information processing visible to team members, students can easily track and comprehend what others say, even if $\mathrm{s} /$ he is not online at that time (Leonardi, 2014; Treem \& Leonardi, 2012). Thus, information processing activities make the team communication more open. Furthermore, because of the convenience of social media, one can easily share information with and ask questions to others without the limitation of space and time.

Therefore, information processing through social media makes team communication in open and distributed learning more frequent and simpler (Chen \& Bryer, 2012). In addition, according to the theory of communication visibility, social connection via social media is believed to make the social networks among students become translucent (Leonardi, 2014), students can easily connect with other team members and access their ideas and suggestions even if they were not friends before (Leonardi, 2015). Therefore, social connection facilitates communication among students become more spontaneous and informal (Treem \& Leonardi, 2012). Therefore, taken together, we hypothesize that:

Hypothesis 1c: Information processing is positively related to the quality of team communication in collaborative learning.

Hypothesis 1d: Social connection is positively related to the quality of team communication in collaborative learning.

\section{The Impact of Coordination Mechanisms on Teamwork Outcomes}

A certain level of TMSs entails recognition of expertise location, mutual trust in other members' knowledge and capability to coordinate among students according to task structure (Lewis, 2004). Prior researches have confirmed that TMSs is a promising approach to orchestrate various roles and 
resources of students in collaborative learning as well as its positive effect on learning performance (Kanawattanachai \& Yoo, 2007; Noroozi, Teasley, Biemans, Weinberger, \& Mulder, 2013). Firstly, because of the existence of a common knowledge map within the team, students can anticipate others' behavior (Kanawattanachai \& Yoo, 2007); thus, the alignments of actions among team members can leverage the team to function smoothly. As a consequence, this can improve the task performance and students' satisfaction with work at the same time. Secondly, heterogeneous knowledge owned by different members contributes to the efficiency of knowledge sharing and application (Choi, Lee, \& Yoo, 2010). As a result, TMSs facilitates problem solving and task completion, and extend students' scope of knowledge (Noroozi et al., 2013). Therefore, we hypothesize that:

H2a: TMSs is positively related to task performance of collaborative learning.

H2b: TMSs is positively related to personal success of collaborative learning.

The existing studies widely agree that the communication quality positively influences collaborative learning outcomes (Joksimović, Gašević, Loughin, Kovanović, \& Hatala, 2015; Kanawattanachai \& Yoo, 2007). Effective communication is believed to bring students closer to the learning goal and bring teams with learning of contents and affective benefits whether in traditional or online learning settings (Joksimović et al., 2015; Yacci, 2000). For example, communication can help to mitigate the complexity and uncertainty of teamwork, resolve interpersonal tasks and team conflicts, and share ideas and knowledge. Thus, communication contributes to completing tasks efficiently and effectively and enhancing the growth of students. Therefore, we hypothesize that:

H2c: Communication is positively related to task performance of collaborative learning.

H2d: Communication is positively related to personal success of collaborative learning.

\section{The Relationship between Communication and TMSs}

Prior studies found that successful teams communicate more intensely at the beginning, while they communicate moderately toward the end (Espinosa et al., 2004). Through communication students get to know each other well and gain meta-knowledge about the expertise of their partners even in online settings (Joksimović et al., 2015; Kanawattanachai \& Yoo, 2007); that is, common team cognition is formed within the team. Although other studies think that effective TMSs can facilitate communication effectiveness (Hsu, Shih, Chiang, \& Liu, 2012), in our study on open and distributed learning, students know little about each other at the beginning and TMSs is formed after they have collaborated for some time, so we hypothesize that:

H3: Communication can facilitate the development of TMSs in collaborative learning. 


\section{Method}

\section{Participants}

All participants are graduate students on an eight-week business analytics course, who were randomly assigned to 40, four-member teams. They were required to complete an authentic research report which included data extraction and analysis, case study, report writing, and presentations in the form of team collaboration. Additionally, they were encouraged to progress the collaboration process on specific social media platforms - Slack and Wechat. Slack is a kind of professional tool for team communication and collaboration. Besides, it is also the one that the teacher asked them to use, because Slack can provide open forums for students to discuss questions and share documents, and the teacher can easily monitor the progress of each team and provide them with suggestions as well as guidelines. Therefore, students mainly adopt Slack for online collaboration. However, Slack lacks the self-presentation functions, such as status updates, so students indicated that they usually add their team members as "friends" on Wechat (a kind of public social media), and follow their status through Moments (the most used function of Wechat) to get to know them in depth and interact with them via Wechat sometimes.

During the eight weeks, to mitigate common method bias, we conducted two surveys to collect data from the class in the fourth and eighth weeks, respectively, because some students omitted to answer one of the two surveys and some students failed to answer the surveys completely. Finally, 25 students' records were removed from the research; this left 135 participants and 40 teams for the data analysis. The size of the teams ranges from 3-4 members, with an average of 3.34 individuals per team. The age average of team members is 22.74 years ( $\mathrm{S} . \mathrm{D}=1.63)$, and there are 89 females and 46 males; 131 students are first-year postgraduates and four are second-year postgraduates. In addition to 124 Chinese students, 11 international students (from Korea, Thailand, Russia, Indonesia, Portugal, Ukraine, Benin, Cambodia, and Laos) participated.

\section{Measures}

The data for the independent variables and mediator variables were collected through the first survey and data for the dependent variables were collected during the second survey. Wherever possible, all questions were adapted and developed based on existing scales to enhance validity. All constructs were assessed using a 7-point Likert scale ranging from 1 (strongly disagree or never) to 7 (strongly agree or very frequently). We adopted a backward translation to ensure consistency between the Chinese and original English version since there were some foreign students amongst the participants, in addition to creating English language questionnaires.

Task performance was assessed with five items that were developed and used by Zellmer-Bruhn and Gibson (2006) to measure how well the teams completed the teamwork required for the research report. We adopted the scales developed and validated by Hoegl and Gemuenden (2001) to measure personal success. These items focus on the people-related success of the teamwork, including work 
satisfaction and personal learning effectiveness. Four items that measured communication were adapted from Hoegl and Gemuenden (2001) to assess the quality of team communication from the aspects of frequency, structure, formalization, and openness. Questions about the TMSs variable are based on the work of Borgatti and Cross (2003), which has fewer items than the one developed by Lewis (2003), and with high reliability and validity. Two kinds of social media activities - information processing and social connection were measured with the scales developed by Ko, Cho, and Roberts (2005). The summary of constructs operationalization is presented in the Appendix. The descriptive statistics of the variables are given in Table 1.

Table 1

Descriptive Statistics of Variables

\begin{tabular}{|l|l|l|l|l|l|}
\hline Constructs & Abbreviation & Min & Max & Mean & Standard deviation \\
\hline Information processing & IP & 2 & 7 & 5.18 & 0.88 \\
\hline Social connection & SC & 2.67 & 7 & 5.32 & 0.84 \\
\hline Communication & CO & 3.25 & 7 & 5.65 & 0.77 \\
\hline Transactive memory systems & TMS & 3.33 & 7 & 5.37 & 0.73 \\
\hline Task performance & TP & 3 & 7 & 6.05 & 0.79 \\
\hline Personal success & PS & 1.63 & 7 & 5.64 & 0.76 \\
\hline
\end{tabular}

\section{Results}

Partial least squares (PLS) analysis is used for data analysis in this research. PLS is widely applied to cope with small-to-medium-sized samples and is suitable for predictive models and theory building (Chin, Marcolin, \& Newsted, 2003). Smart PLS version 3.0 is the tool we used to analyze our model.

\section{Measurement Analysis}

Individual level reliability and validity. In this research, we tested the reliability of all variables through Cronbach's alpha $(\mathrm{C} \alpha)$ value, and assessed convergent validity by calculating Composite Reliability (CR) and Average Variance Extracted (AVE) at each individual level. All Ca values of variables exceed 0.7, suggesting a good reliability (Nunnally, Bernstein, \& Berge, 1967). All CR is above 0.7, and AVE is higher than 0.5, so the scales have good convergent validity. Discriminant validity was assessed by Fornell-Larcker Criterion (FLC) and Cross Loadings (CL). All items have acceptable loadings on their intended construct. Furthermore, the values of square root of AVE are all higher than its correlation coefficients with other constructs; this suggest a good discriminant validity (Fornell \& Larcker, 1981) 
Aggregation analysis. Data on the variables were collected at the individual level. Before aggregating individual responses to team level, it is necessary to test the conformity of the level of measurement to the level of the theoretical analysis. We tested within-group agreement by considering the $\mathrm{R}_{\mathrm{wg}}$ and the ICC indices (James, Demaree, \& Wolf, 1984). As the results demonstrated in Table 2, each $\mathrm{F}$ value that tests ICC's significance is significant, indicating that team level analysis is more appropriate than individual level. As to the value of $\mathrm{R}_{\mathrm{wg}}$, the average values are all higher than the cut-off value of 0.7 , suggesting within-group agreement reach the acceptable level.

Table 2

Results of ICC and $R_{w g}$

\begin{tabular}{|l|l|l|l|l|l|}
\hline & ICC1 & ICC2 & F & P & $R_{\text {wg }}$ \\
\hline IP & 0.27 & 0.57 & 2.322 & $<0.01$ & 0.90 \\
\hline SC & 0.20 & 0.48 & 1.908 & $<0.01$ & 0.86 \\
\hline CO & 0.26 & 0.55 & 2.149 & $<0.01$ & 0.93 \\
\hline TMS & 0.15 & 0.39 & 1.636 & $<0.05$ & 0.92 \\
\hline PS & 0.15 & 0.38 & 1.621 & $<0.05$ & 0.96 \\
\hline TP & 0.19 & 0.45 & 1.817 & $<0.01$ & 0.95 \\
\hline
\end{tabular}

Team level of reliability and validity. Table 3 displays the reliability and validity test results. The $\mathrm{Ca}$ values of each construct are above 0.7 , indicating good reliability. In terms of convergent validity, composite reliability values range from 0.89 to 0.96 , which indicates adequate composite reliability. In addition, the AVE value of each construct is higher than the acceptable level (0.5), demonstrating that all constructs in this study have adequate convergent validity.

According to the results of $\mathrm{CL}$, two questions for personal success tapped into other constructs and were removed. After removing these two items, as presented in Table 4, all other items have loadings higher than the acceptable level. And the square root of AVE in Table 3 (figures in bold) is higher than its correlation coefficients with other constructs; suggesting an adequate discriminant validity (Fornell \& Larcker, 1981).

Table 3

Results of Team Level Reliability and Validity Test 


\begin{tabular}{|l|l|l|l|l|l|l|l|l|l|l|}
\hline Construct & Abb. & Ca & CR & AVE & IP & SC & CO & TMS & PS & TP \\
\hline Information processing & IP & 0.83 & 0.89 & 0.75 & $\mathbf{0 . 9 1 7}$ & & & & \\
\hline Social connection & SC & 0.86 & 0.91 & 0.79 & 0.727 & $\mathbf{0 . 8 9}$ & & & \\
\hline Communication & CO & 0.91 & 0.94 & 0.8 & 0.58 & 0.665 & $\mathbf{0 . 8 9 6}$ & & \\
\hline Transactive memory & TMS & 0.84 & 0.9 & 0.76 & 0.73 & 0.778 & 0.692 & $\mathbf{0 . 8 7 5}$ & \\
\hline systems & & & & & & & & & \\
\hline Personal success & PS & 0.88 & 0.91 & 0.69 & 0.353 & 0.509 & 0.578 & 0.582 & $\mathbf{0 . 8 3 2}$ & \\
\hline Task performance & TP & 0.95 & 0.96 & 0.85 & 0.392 & 0.463 & 0.69 & 0.663 & 0.663 & $\mathbf{0 . 9 2 2}$ \\
\hline
\end{tabular}

Table 4

Team Level Cross Loadings

\begin{tabular}{|l|l|l|l|l|l|l|}
\hline & CO & IP & SC & TMS & TP & PS \\
\hline CO1 & $\mathbf{0 . 8 6 3}$ & 0.454 & 0.541 & 0.508 & 0.600 & 0.512 \\
\hline CO2 & $\mathbf{0 . 9 1 7}$ & 0.421 & 0.604 & 0.586 & 0.602 & 0.541 \\
\hline CO3 & $\mathbf{0 . 9 2 1}$ & 0.601 & 0.582 & 0.649 & 0.667 & 0.477 \\
\hline CO4 & $\mathbf{0 . 8 8 1}$ & 0.602 & 0.648 & 0.718 & 0.603 & 0.568 \\
\hline IP1 & 0.537 & $\mathbf{0 . 8 8 4}$ & 0.716 & 0.678 & 0.280 & 0.349 \\
\hline IP2 & 0.447 & $\mathbf{0 . 8 2 0}$ & 0.622 & 0.558 & 0.393 & 0.276 \\
\hline IP3 & 0.524 & $\mathbf{0 . 8 8} 7$ & 0.616 & 0.648 & 0.356 & 0.286 \\
\hline SC1 & 0.561 & 0.709 & $\mathbf{0 . 8 3 8}$ & 0.637 & 0.388 & 0.305 \\
\hline SC2 & 0.588 & 0.682 & $\mathbf{0 . 9 4 0}$ & 0.762 & 0.455 & 0.531 \\
\hline SC3 & 0.617 & 0.629 & $\mathbf{0 . 8 8 9}$ & 0.675 & 0.392 & 0.511 \\
\hline TMS1 & 0.533 & 0.648 & 0.693 & $\mathbf{0 . 8 7 2}$ & 0.518 & 0.605 \\
\hline TMS2 & 0.605 & 0.610 & 0.664 & $\mathbf{0 . 8 6 2}$ & 0.672 & 0.499 \\
\hline TMS3 & 0.678 & 0.657 & 0.685 & $\mathbf{0 . 8 9 0}$ & 0.545 & 0.428 \\
\hline TP1 & 0.664 & 0.368 & 0.367 & 0.567 & $\mathbf{0 . 9 0 8}$ & 0.559 \\
\hline TP2 & 0.617 & 0.272 & 0.419 & 0.588 & $\mathbf{0 . 9 3 5}$ & 0.590 \\
\hline TP3 & 0.665 & 0.429 & 0.445 & 0.649 & $\mathbf{0 . 9 4 0}$ & 0.574 \\
\hline
\end{tabular}




\begin{tabular}{|l|l|l|l|l|l|l|}
\hline TP4 & 0.657 & 0.428 & 0.491 & 0.718 & $\mathbf{0 . 9 1 9}$ & 0.692 \\
\hline TP5 & 0.571 & 0.290 & 0.405 & 0.511 & $\mathbf{0 . 9 0 9}$ & 0.637 \\
\hline PS1 & 0.554 & 0.481 & 0.575 & 0.557 & 0.581 & $\mathbf{0 . 8 0} 7$ \\
\hline PS2 & 0.494 & 0.287 & 0.422 & 0.496 & 0.495 & $\mathbf{0 . 8 6 1}$ \\
\hline PS5 & 0.462 & 0.267 & 0.446 & 0.501 & 0.595 & $\mathbf{0 . 8 2 8}$ \\
\hline PS6 & 0.378 & 0.231 & 0.328 & 0.396 & 0.537 & $\mathbf{0 . 8 5 7}$ \\
\hline PS7 & 0.480 & 0.153 & 0.298 & 0.449 & 0.536 & $\mathbf{0 . 8 0 6}$ \\
\hline
\end{tabular}

\section{Structural Model Assessment}

Analysis of the Structural Model is the second stage in the SEM. We calculated the significance of path coefficients with the help of Smart PLS by bootstrapping with 5000 samples using the replacement method. The analysis results are displayed in Figure 2.

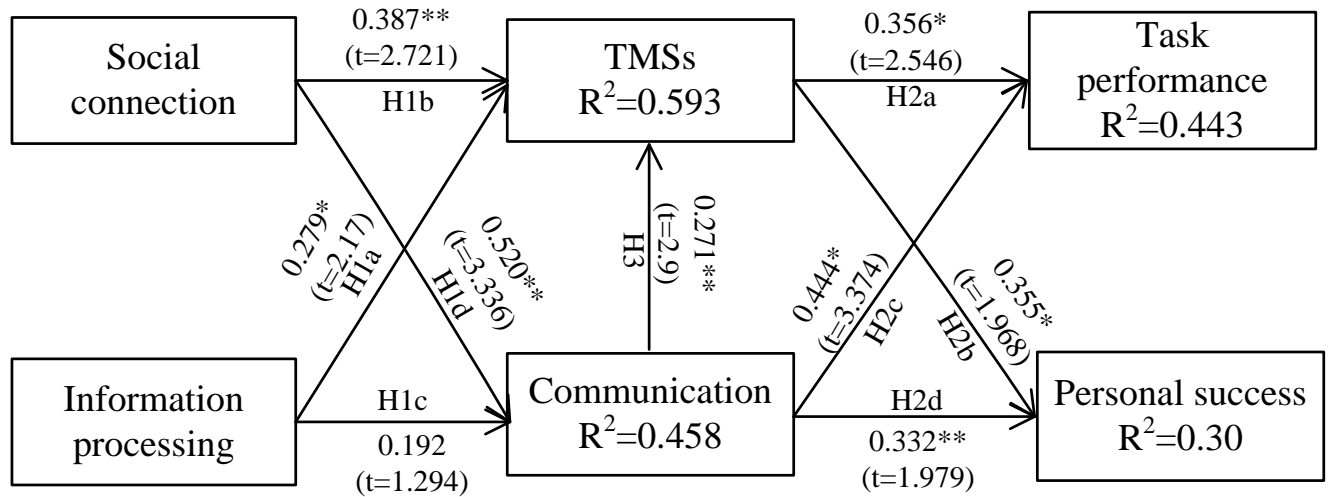

$* \mathrm{p}<0.05, * * \mathrm{p}<0.01, * * * \mathrm{p}<0.001$

Figure 2. Results of PLS analysis.

As shown in Figure 2, $\mathrm{R}^{2}$ of personal success is 0.30 , and $\mathrm{R}^{2}$ of task performance is 0.443 . As hypothesized, TMSs are significantly related to personal success (path coefficient $=0.355$, t-value $=1.968, p<0.05$ ) and task performance (path coefficient $=0.356$, $t$-value $=2.546, p<0.05$ ), thus $\mathrm{H} 2 \mathrm{a}$ and $\mathrm{H} 2 \mathrm{~b}$ are supported. Communication is also significantly associated with personal success (path coefficient $=0.332, \mathrm{t}$-value $=1.979, \mathrm{p}<0.05$ ) and task performance (path coefficient $=0.444$, $\mathrm{t}$-value $=3.374, \mathrm{p}<0.01$ ), supporting H2c and H2d. With regard to the two kinds of social media use, information processing is positively related to TMSs (path coefficient $=0.279, t$-value $=2.17, p<0.05$ ), while its effect on communication is not significant; that is, H1a is supported, but H1c is not supported. The effects that the use of social connection activities have on communication (path coefficient $=0.520$, $\mathrm{t}$-value $=3.336, \mathrm{p}<0.001$ ) and TMSs (path coefficient $=0.387$, $\mathrm{t}$-value $=2.721, \mathrm{p}<0.01$ ) are all significant. Therefore, H1b and H1d are supported. And, last, the relationship between communication and TMSs is significantly positive (path coefficient $=0.271$, $t$-value $=2.90, p<0.01$ ), so $\mathrm{H}_{3}$ is also supported. 


\section{Mediation Analysis}

We tested the mediation effects of communication and TMSs based on the three steps described by Baron and Kenny (1986). Firstly, we tested whether the relationship between independent variable (IV) and dependent variable (DV) is significant. Secondly, we estimated whether the independent variable can significantly affect the mediator (M). Lastly, we tested whether the DV is significantly affected by the IV while the mediator is consistent. The results of the mediation analysis are displayed in Table 5 .

Table 5

Results of Mediation Analysis

\begin{tabular}{|l|l|l|l|l|l|l|l|}
\hline \multicolumn{2}{|l|}{ Mediation path } & \multicolumn{2}{l}{ Path coefficient } & Mediation \\
effect
\end{tabular}

${ }^{*} \mathrm{p}<0.05,{ }^{* *} \mathrm{p}<0.01,{ }^{* * *} \mathrm{p}<0.001$

As Table 5 shows, we found that TMSs completely mediates the relationship between the two kinds of social media activities (information processing and social connection) and two dimensions of teamwork outcomes (personal success and task performance); however, TMSs partially mediates the relationship between communication and two dependent variables - personal success and task performance. In addition, communication completely mediates the relationship between social connection and teamwork outcomes (personal success and task performance), and partially mediates the relationship between TMSs and social connection. 


\section{Discussion}

This study aims to investigate the effects of social media activities on teamwork outcomes in collaborative learning through the process of coordination. The empirical results show that two coordination mechanisms of explicit and implicit coordination play important roles in the relationship between social media and teamwork outcomes. As hypothesized, communication has a significant positive impact on task performance and personal success of students. In order to complete tasks and gain knowledge in this distributed collaborative learning, knowledge and ideas need to be integrated and students claimed that they could learn new knowledge and creativity was usually stimulated through communication. These results have consistency with prior studies (Hoegl \& Gemuenden, 2001; Yacci, 2000). Except for communication, which has been widely confirmed to enhance team performance, TMSs as one of the implicit coordination mechanisms, can also improve personal success and task performance. These findings are consistent with prior studies (Choi et al., 2010; Kanawattanachai \& Yoo, 2007). When the level of TMSs is high, students can act in concert in the collaboration and feel satisfied because of the common meta-knowledge about the expertise of their team members and mutual trust in their abilities. From the observation of the path coefficients, communication contributes more than TMSs contributes to task performance, while TMSs is more beneficial than communication to personal success. This implies that explicit manner is more effective to task completion in this collaborative learning, while students gain more satisfaction on this collaborative learning through harmoniously implicit manner. In addition, the relationship between communication and TMSs is significant. As hypothesized, the good communication quality in collaboration can facilitate students to know each other in depth and then form a high level of TMSs, which is consistent with the research of Kanawattanachai and Yoo (2007).

As to social media activities, we find that both information processing and social connection have a positive impact on TMSs. The results confirm the proposition of communication visibility theory. Social media can improve team members' meta-knowledge about "who knows what" and "who knows whom," which are the core component of TMSs (Leonardi, 2014). As to the effect of social media activities on communication, it has previously been shown that social connection can improve communication quality. However, we find that information processing does not significantly affect communication quality. This result is a bit of contrary to our common sense. Such a finding may be caused by the environment of the team collaboration. In our study, students collaborated via multi-channels, not just social media like Wechat and Slack. Although students were encouraged to adopt social media to collaborate with their team members, they indicated that, when team members convened for discussions on social media, they often missed some important information because they generated too many messages simultaneously, and therefore, would feel confused about the discussion (Leonardi, Huysman, \& Steinfield, 2013). What is more, compared with face-to-face communication, the communication context on social media is simpler. That is, team members do not have tone, facial expression or other body language to help them judge other members' meanings. As a result, misunderstandings and frustration could occur among them (Capdeferro \& Romero, 2012). In 
addition, social media can lead to a lack of accountability; team members can take advantage of this weakness by "social loafing," because individuals' actions in group discussion can hardly be monitored by others (Boughzala, De Vreede, \& Limayem, 2012). Therefore, team leaders' control over the discussion via social media is lower than during face-to-face interaction. Thus, they indicated that they were inclined to use Slack for announcements, task allocation and other routine activities, while they mainly adopted offline meetings for team discussion to solve difficult problems.

\section{Implications and Limitations}

Furthermore, the results of social media activities' effects on teamwork outcomes also provide us with both educational and academic implications. On one hand, for education, firstly, in order to improve outcomes of collaborative learning, students and teachers should pay attention to both team explicit coordination (e.g., communication) and implicit coordination (e.g., TMSs). Secondly, in light of the relationship between communication and TMSs, teachers should guide the students to improve the quality of team communication at the initial state of collaboration to leverage the formation of shared understanding about the task as well as the familiarity of team members. Therefore, team members can coordinate implicitly and smartly in the later state of collaborative learning. Lastly, the results are expected to provide educational insights into how to make better use of social media through focusing on different kinds of social media use. Our research results show that, in this distributed collaborative learning context, students tend to adopt social connection to build ties and deepen the understanding of their team members, and then advance offline communication. Therefore, teachers can encourage students to apply social media to this distributed collaborative learning. Specifically, students can present their personal profiles with more comprehensive information and add team members as "friends" on social media to facilitate members to know more about each other. In addition, teachers should take some incentive measures to foster students' task-oriented interaction on social media to overcome the problem of social loafing, importantly, team leaders should guide the discussion on social media and release plan for the next step timely on the social media to reduce members' confusion and frustration.

On the other hand, for academia, firstly, this study broadens our understanding about the effects of social media use on teamwork in open and distributed learning setting from two aspects, information processing and social connection, which is different to most past research that has investigated social media use in a work context from one aspect, such as use frequency. And our study shows that social media use for social connection are more beneficial to team coordination process than information processing in this collaborative learning. Secondly, we explore the relationship between social media use and teamwork outcomes of collaborative learning from both explicit and implicit coordination perspectives, and try to examine their relationship. Both explicit manner (communication) and implicit manner (TMSs) can facilitate to enhance collaborative learning outcomes. Specifically, communication is more beneficial for task performance, while TMSs contributes more to students' learning and satisfaction on collaboration. Thus, this study has the potential to contribute to the 
literature of coordination research in open and distributed learning.

However, our study still remains many limitations and questions. The first limitation is the relatively small sample size of the investigation, which limits the options for data analysis and reduces the external validity of results. Future studies should investigate this topic with more data. Secondly, our study only investigates the effects of two kinds of social media activity on teamwork. Then, what are the effects of entertainment activities on teamwork outcomes? In addition, the context of collaborative learning in this study is multi-channel, where social media is just one of many collaborative channels. Thus, what is the role or effect of social media in teamwork in the virtual environment where all interactions are social media-enabled? Therefore, there are still several limitations and many questions remained in this study that deserve further research.

\section{Conclusion}

The key conclusion of this study is that social media activities can have positive effects on teamwork outcomes through enhancing the team coordination process in distributed collaborative learning. By compiling the data for 40 teams, the results identify that mechanisms of both explicit coordination and implicit coordination, known as communication and TMSs, can improve task performance as well as personal success. Furthermore, the level of TMSs can be advanced by communication. As to social media, the results demonstrate that both social connection and information processing can improve the level of TMSs, which confirms the propositions of communication visibility theory; however, communication is only positively affected by social connection and cannot be significantly improved by information processing in our study context. Some possible reasons, limitations and extended questions about the factors and relations unfolded in this study that need to be investigated in the future study have been discussed.

\section{Acknowledgement}

The study is supported by funds from National Natural Science Foundation of China [No: 71201155 and 71571133], and High Level Foreign Expert Project of State Administration of Foreign Experts Affairs P.R. China [GDW20161200257].

\section{References}

Al-Rahmi, W., \& Othman, M. (2013). The impact of social media use on academic performance among university students: A pilot study. Journal of Information Systems Research and Innovation, 4, 
$1-10$

Al-Rahmi, W., Othman, M. S., \& Yusuf, L. M. (2015). the role of social media for collaborative learning to improve academic performance of students and researchers in malaysian higher education. The International Review of Research in Open and Distributed Learning, 16(4).

Baron, R. M., \& Kenny, D. A. (1986). The moderator-mediator variable distinction in social psychological research: Conceptual, strategic, and statistical considerations. Journal of Personality and Social Psychology, 51(6), 1173.

Borgatti, S. P., \& Cross, R. (2003). A relational view of information seeking and learning in social networks. Management Science, 49(4), 432-445.

Boughzala, I., De Vreede, G.-J., \& Limayem, M. (2012). Team collaboration in virtual worlds: Editorial to the special issue. Journal of the Association for Information Systems, 13(10), 714-734.

Capdeferro, N., \& Romero, M. (2012). Are online learners frustrated with collaborative learning experiences? The International Review of Research in Open and Distributed Learning, 13(2), 26-44.

Casey, G., \& Evans, T. (2011). Designing for learning: Online social networks as a classroom environment. The International Review of Research in Open and Distributed Learning, 12(7), 1-26.

Chen, B., \& Bryer, T. (2012). Investigating instructional strategies for using social media in formal and informal learning. The International Review of Research in Open and Distributed Learning, 13(1), 87-104.

Chin, W. W., Marcolin, B. L., \& Newsted, P. R. (2003). A partial least squares latent variable modeling approach for measuring interaction effects: Results from a Monte Carlo simulation study and an electronic-mail emotion/adoption study. Information Systems Research, 14(2), 189-217.

Choi, S. Y., Lee, H., \& Yoo, Y. (2010). The impact of information technology and transactive memory systems on knowledge sharing, application, and team performance: A field study. MIS Quarterly, 34(4), 855-870.

Cooley, S. J., Burns, V. E., \& Cumming, J. (2015). The role of outdoor adventure education in facilitating groupwork in higher education. Higher Education, 69(4), 567-582.

Dehler, J., Bodemer, D., Buder, J., \& Hesse, F. W. (2011). Guiding knowledge communication in CSCL via group knowledge awareness. Computers in Human Behavior, 27(3), 1068-1078.

Dabbagh, N., \& Kitsantas, A. (2012). Personal learning environments, social media, and self-regulated 
learning: A natural formula for connecting formal and informal learning. The Internet and Higher Education, 15(1), 3-8.

DeChurch, L. A., \& Mesmer-Magnus, J. R. (2010). The cognitive underpinnings of effective teamwork: a meta-analysis. Journal of Applied Psychology, 95(1), 32.

DiMicco, J., Millen, D. R., Geyer, W., Dugan, C., Brownholtz, B., \& Muller, M. (2008). Motivations for social networking at work. ACM conference on Computer supported cooperative work.

Espinosa, J. A., Lerch, F. J., \& Kraut, R. E. (2004). Explicit versus implicit coordination mechanisms and task dependencies: One size does not fit all. In E. Salas \& S.M. Fiore (Eds.), Team cognition: understanding the factors that drive process and performance (pp. 107-129). Washington, DC: APA Books.

Faraj, S., \& Sproull, L. (2000). Coordinating expertise in software development teams. Management Science, 46(12), 1554-1568.

Fisher, D. M., Bell, S. T., Dierdorff, E. C., \& Belohlav, J. A. (2012). Facet personality and surface-level diversity as team mental model antecedents: implications for implicit coordination. Journal of Applied Psychology, 97(4), 825.

Fornell, C., \& Larcker, D. F. (1981). Evaluating structural equation models with unobservable variables and measurement error. Journal of Marketing Research, 18(1), 39-50.

Gibbons, D. E. (2004). Friendship and advice networks in the context of changing professional values. Administrative Science Quarterly, 49(2), 238-262.

Godart, C., Bouthier, C., Canalda, P., Charoy, F., Molli, P., Perrin, O. et al. (2001). Asynchronous coordination of virtual teams in creative applications (co-design or co-engineering): Requirements and design criteria. Australian Computer Science Communications, 23(6), 135-142.

Griffith, T. L., \& Neale, M. A. (2001). Information processing in traditional, hybrid, and virtual teams: From nascent knowledge to transactive memory. Research in Organizational Behavior, 23, $379-421$.

Heinonen, K. (2011). Consumer activity in social media: Managerial approaches to consumers' social media behavior. Journal of Consumer Behaviour, 10(6), 356-364.

Hoegl, M., \& Gemuenden, H. G. (2001). Teamwork quality and the success of innovative projects: A theoretical concept and empirical evidence. Organization Science, 12(4), 435-449.

Hsu, J. S.-C., Shih, S.-P., Chiang, J. C., \& Liu, J. Y.-C. (2012). The impact of transactive memory 
systems on IS development teams' coordination, communication, and performance. International Journal of Project Management, 30(3), 329-340.

James, L. R., Demaree, R. G., \& Wolf, G. (1984). Estimating within-group interrater reliability with and without response bias. Journal of Applied Psychology, 69(1), 85.

Joksimović, S., Gašević, D., Loughin, T. M., Kovanović, V., \& Hatala, M. (2015). Learning at distance: Effects of interaction traces on academic achievement. Computers \& Education, 87, 204-217.

Kanawattanachai, P., \& Yoo, Y. (2007). The impact of knowledge coordination on virtual team performance over time. MIS Quarterly, 31(4), 783-808.

Kaplan, A. M., \& Haenlein, M. (2010). Users of the world, unite! The challenges and opportunities of Social Media. Business Horizons, 53(1), 59-68.

Kietzmann, J. H., Hermkens, K., McCarthy, I. P., \& Silvestre, B. S. (2011). Social media? Get serious! Understanding the functional building blocks of social media. Business Horizons, 54, 241-251.

Ko, H., Cho, C.-H., \& Roberts, M. S. (2005). Internet uses and gratifications: A structural equation model of interactive advertising. Journal of Advertising, 34(2), 57-70.

Kotlarsky, J., van den Hooff, B., \& Houtman, L. (2013). Are we on the same page? Knowledge boundaries and transactive memory system development in cross-functional teams. Communication Research, 42(3), 319-344.

Kotlarsky, J., Van Fenema, P. C., \& Willcocks, L. P. (2008). Developing a knowledge-based perspective on coordination: The case of global software projects. Information \& Management, 45(2), 96-108.

Kwon, K., Hong, R.-Y., \& Laffey, J. M. (2013). The educational impact of metacognitive group coordination in computer-supported collaborative learning. Computers in Human Behavior, 29(4), 1271-1281.

Leonardi, P. M. (2014). Social media, knowledge sharing, and innovation: Toward a theory of communication visibility. Information Systems Research, 25(4), 796-816.

Leonardi, P. M. (2015). Ambient awareness and knowledge acquisition: Using social media to learn" who knows what" and" who knows whom". MIS Quarterly, 39(4), 747-762.

Leonardi, P. M., Huysman, M., \& Steinfield, C. (2013). Enterprise social media: Definition, history, and prospects for the study of social technologies in organizations. Journal of Computer-Mediated Communication, 19(1), 1-19.

Leonardi, P. M., \& Treem, J. W. (2012). Knowledge management technology as a stage for strategic 
self-presentation: Implications for knowledge sharing in organizations. Information and Organization, 22(1), 37-59.

Lewis, K. (2003). Measuring transactive memory systems in the field: scale development and validation. Journal of Applied Psychology, 88(4), 587.

Lewis, K. (2004). Knowledge and performance in knowledge-worker teams: A longitudinal study of transactive memory systems. Management science, 5o(11), 1519-1533.

Lin, J.-W., Szu, Y.-C., \& Lai, C.-N. (2016). Effects of group awareness and self-regulation level on online learning behaviors. The International Review of Research in Open and Distributed Learning, 17(4).

Malone, T. W., \& Crowston, K. (1994). The interdisciplinary study of coordination. ACM Computing Surveys (CSUR), 26(1), 87-119.

Mbati, L. (2013). Online social media applications for constructivism and observational learning. The International Review of Research in Open and Distributed Learning, 14(5).

McLoughlin, C., \& Lee, M. J. (2010). Personalised and self regulated learning in the Web 2.0 era: International exemplars of innovative pedagogy using social software. Australasian Journal of Educational Technology, 26(1).

Mohammed, S., \& Dumville, B. C. (2001). Team mental models in a team knowledge framework: Expanding theory and measurement across disciplinary boundaries. Journal of Organizational Behavior, 22(2), 89-106.

Noroozi, O., Teasley, S. D., Biemans, H. J., Weinberger, A., \& Mulder, M. (2013). Facilitating learning in multidisciplinary groups with transactive CSCL scripts. International Journal of Computer-Supported Collaborative Learning, 8(2), 189-223.

Nunnally, J. C., Bernstein, I. H., \& Berge, J. M. t. (1967). Psychometric theory (Vol. 226). New York: McGraw-Hill.

Prichard, J. S., Stratford, R. J., \& Bizo, L. A. (2006). Team-skills training enhances collaborative learning. Learning and Instruction, 16(3), 256-265.

Ravenscroft, A. (2011). Dialogue and connectivism: A new approach to understanding and promoting dialogue-rich networked learning. The International Review of Research in Open and Distributed Learning, 12(3), 139-160.

Ren, Y., \& Argote, L. (2011). Transactive memory systems 1985-2010: An integrative framework of key dimensions, antecedents, and consequences. The Academy of Management Annals, 5(1), 
189-229.

Rico, R., Sánchez-Manzanares, M., Gil, F., \& Gibson, C. (2008). Team implicit coordination processes: A team knowledge-based approach. Academy of Management Review, 33(1), 163-184.

Shao, G. (2009). Understanding the appeal of user-generated media: a uses and gratification perspective. Internet Research, 19(1), 7-25.

Stafford, T. F., Stafford, M. R., \& Schkade, L. L. (2004). Determining uses and gratifications for the Internet. Decision Sciences, 35(2), 259-288.

Treem, J. W., \& Leonardi, P. M. (2012). Social media use in organizations: Exploring the affordances of visibility, editability, persistence, and association. Communication Yearbook, 36, 143-189.

Van den Bossche, P., Gijselaers, W. H., Segers, M., \& Kirschner, P. A. (2006). Social and cognitive factors driving teamwork in collaborative learning environments team learning beliefs and behaviors. Small Group Research, 37(5), 490-521.

Wegner, D. M. (1987). Transactive memory: A contemporary analysis of the group mind Theories of group behavior (pp. 185-208). New York: Springer.

Wheeler, S., Yeomans, P., \& Wheeler, D. (2008). The good, the bad and the wiki: Evaluating student-generated content for collaborative learning. British Journal Of Educational Technology, 39(6), 987-995.

Yacci, M. (2000). Interactivity demystified: A structural definition for distance education and intelligent CBT. Educational Technology, 4O(4), 5-16.

Zellmer-Bruhn, M., \& Gibson, C. (2006). Multinational organization context: Implications for team learning and performance. Academy of Management Journal, 49(3), 501-518. 
Coordinated Implicitly? An Empirical Study on the Role of Social Media in Collaborative Learning

Zhang, Chen, Ordóñez de Pablos, Lytras, and Sun 


\section{Appendix}

\section{Operationalization of Constructs}

\begin{tabular}{|c|c|c|}
\hline Constructs & Item wording and code & source \\
\hline $\begin{array}{l}\text { Social connection } \\
\text { (SC) }\end{array}$ & $\begin{array}{l}\text { I wonder what other people said (SC1) } \\
\text { To express myself freely (SC2) } \\
\left.\text { To meet people with my Interests ( } \mathrm{SC}_{3}\right)\end{array}$ & \multirow[t]{2}{*}{$\begin{array}{l}\text { Ko, Cho, and } \\
\text { Roberts (2005) }\end{array}$} \\
\hline $\begin{array}{l}\text { Information } \\
\text { processing (IP) }\end{array}$ & $\begin{array}{l}\text { To learn about unknown things (IP1) } \\
\text { It's a good way to do research (IP2) } \\
\text { To learn about useful things (IP3) }\end{array}$ & \\
\hline $\begin{array}{l}\text { Transactive memory } \\
\text { systems (TMS) }\end{array}$ & $\begin{array}{l}\text { I understand what skills my team members have and } \\
\text { domains they are knowledgeable in (TMS1) } \\
\text { My team members have expertise in areas that are } \\
\text { important in the kind of work I do (TMS2) } \\
\text { Overall, I am able to access other team members' } \\
\text { thinking and knowledge (TMS3) }\end{array}$ & $\begin{array}{l}\text { Borgatti and Cross } \\
(2003)\end{array}$ \\
\hline $\begin{array}{l}\text { Communication } \\
(\mathrm{CO})\end{array}$ & $\begin{array}{l}\text { There was frequent communication within the team } \\
\text { (CO1) } \\
\text { The team members often communicated spontaneously } \\
(\mathrm{CO} 2) \\
\text { The team members communicated mostly directly and } \\
\text { personally with each other }\left(\mathrm{CO}_{3}\right) \\
\text { Teamwork-relevant information was shared openly by all } \\
\text { team members }(\mathrm{CO} 4)\end{array}$ & $\begin{array}{l}\text { Hoegl and } \\
\text { Gemuenden } \\
\text { (2001) }\end{array}$ \\
\hline $\begin{array}{l}\text { Task performance } \\
\text { (TP) }\end{array}$ & $\begin{array}{l}\text { My team achieves its goals (TP1) } \\
\text { My team accomplishes its objectives (TP2) } \\
\left.\text { My team meets the requirements set for it ( } \mathrm{TP}_{3}\right) \\
\left.\text { My team fulfills its mission ( } \mathrm{TP}_{4}\right) \\
\left.\text { My team serves the purposes it is intended to serve ( } \mathrm{TP}_{5}\right)\end{array}$ & $\begin{array}{l}\text { Zellmer-Bruhn } \\
\text { and Gibson } \\
\text { (2006) }\end{array}$ \\
\hline $\begin{array}{l}\text { Personal success } \\
\text { (PS) }\end{array}$ & $\begin{array}{l}\text { Team members have gained from the teamwork (PS1) } \\
\text { The team members would like to do this type of } \\
\text { teamwork again (PS2) }\end{array}$ & $\begin{array}{l}\text { Hoegl and } \\
\text { Gemuenden } \\
\text { (2001) }\end{array}$ \\
\hline
\end{tabular}




\begin{tabular}{|l|l|l|}
\hline & $\begin{array}{l}\text { After this teamwork, the team members could draw a } \\
\text { positive balance for themselves overall (PS3) } \\
\text { We were able to acquire important know-how through } \\
\text { this teamwork (PS4) } \\
\text { We see this project as a success(PS5) } \\
\text { Our team learned important lessons from this teamwork } \\
\begin{array}{l}\text { (PS6) } \\
\text { Teamwork promotes one personally (PS7) }\end{array}\end{array}$ \\
\hline
\end{tabular}

\section{Athabasca}

University

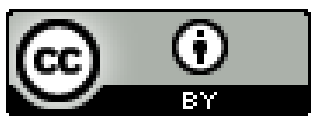

